\title{
Review of: "SURGICAL TREATMENT OF MEDICATION- RELATED OSTEONECROSIS OF THE JAW: TECHNICAL REPORT AND PROGNOSIS ASSESSMENT"
}

\author{
Giovanni Mergoni
}

Potential competing interests: The author(s) declared that no potential competing interests exist.

The topic of the paper is interesting and the results, even if without statistical significance, are useful to set future research. I suggest to report the features of the 13 patients who developed recurrences. 